\title{
Peptidomic Analysis of Endometrial Tissue from Patients with Ovarian Endometriosis
}

\author{
Yunping Xue $\quad$ Pengfei $X u^{a} \quad$ Sujuan $X u^{a, c} \quad K a i X u e^{a, b} \quad$ Lingling Xu ${ }^{b} \quad$ Jie Chen ${ }^{b}$ \\ Juan Xu Xiaoyan Shib Qian Lia, Lin Gu \\ aNanjing Maternal and Child Health Institute, bepartment of Gynecological Endocrinology, \\ cDepartment of Clinical Laboratory, The Affiliated Obstetrics and Gynecology Hospital of Nanjing \\ Medical University (Nanjing Maternity and Child Health Care Hospital), Nanjing, China
}

\section{Key Words}

Proteomics • Ovarian Endometriosis • Liquid chromatography-tandem mass spectrometry

\begin{abstract}
Background/Aims: Ovarian endometriosis (OvE) is ovarian cyst that is lined with endometrial tissue. They are found in $17-44 \%$ of women with endometriosis. Their clinical manifestations include pelvic pain, dysmenorrhea, dyspareunia, and infertility. Although the incidence of OvE has increased yearly, the exact pathogenesis of OvE is still unclear. We used peptidomics, an emerging branch of proteomics, to identify differentially expressed peptides in order to determine the possible roles of these peptides in the pathogenesis of OvE. Methods: The ectopic and eutopic endometria of OvE were used to extract peptides with 10-kDa molecular weight cutoff filters, and the peptide precursor proteins were then identified with PEAKS software, followed by quantification with the TMT labeling method and subsequent analysis by liquid chromatography-tandem mass spectrometry. Gene ontology (GO) analysis, pathway analysis, SMART, and SABLE were used to study the possible functions of these peptide according to their precursor proteins' function. The effects of peptides derived from VCAM1 (PDFV) on endometrial stromal cell (ESC) migration and invasion were examined with wound healing assays and Transwell assays and the expression of E-cadherin was detected by western blotting. Results: A total of 491 peptides were identified with abundant differences between the two groups of samples ( $p<0.05$, and absolute fold change $\geq 2)$. SMART and SABLE database showed that 42 of the 491 peptides were located in the conserved structural domains of their protein precursors and contained secondary structure and, among them, 2 peptides' precursor proteins were associated with the cell proliferation. Additionally, 5 peptides' precursor proteins were associated with endometriosis. Our study confirmed that PDFV promoted ESC migration and invasion and reduced E-cadherin expression $(p<0.05)$. Conclusion: PDFV and its precursor protein VCAM-1 may be involved in the process of OvE formation by reducing the expression of E-cadherin. The peptidomics analysis provides new insight for future studies of the mechanisms of OvE development.
\end{abstract}

Y. Xue, P. Xu and S. Xu contributed equally to this work. 


\section{Introduction}

Endometriosis, one of the most common gynecological diseases in women of reproductive age, is defined as the presence of functional endometrial glands and stroma outside the uterine cavity. Endometriosis is characterized by various typical clinical symptoms, such as pelvic pain, dysmenorrhea, dyspareunia, and infertility. The incidence of endometriosis in women of reproductive age is approximately $10 \%$ [1]. However, the exact pathogenesis of endometriosis is still unclear. The "blood reflux planting theory" of Sampson [2] is the leading theory, but it remains unclear why only some women develop endometriosis, given that retrograde menstruation occurs in most women [3]. Endometriosis has three main different histological subtypes: peritoneal, ovarian, and deep endometriosis [4, 5]. Ovarian endometriosis (OvE) (also known as "chocolate cysts") are ovarian cysts that are lined with endometrial tissue and contain fluid that arises from accumulation of menstrual debris. They are found in $17-44 \%$ of women with endometriosis [6]. Currently, drugs, surgery, and a combination of the two methods are mainly used to treat OvE. Among the surgical methods, laparoscopic resection of the lesion is the preferred method, but the recurrence rate remains high, with a reported 5-year recurrence rate as high as 50\% [7]. In addition, the rate of spontaneous ovulation is lower in operated ovaries and serum levels of anti-Mullerian hormone decrease after surgery. Therefore, identification of a treatment biomarker of OvE from a new perspective is clearly necessary.

Peptidomics is an emerging branch of proteomics through which a large number of both intracellular and secreted mammalian peptides have been identified. Thus, peptidomics has attracted widespread attention in recent years $[8,9]$. Peptides are important bioactive molecules that play important roles in many physiological processes, including endometriosis $[10,11]$. Despite the essential role of peptides in biological processes, the research is lacking due to technological limitations. With recent advances in natural peptide purification and mass spectrometry technology, the peptidome is becoming more central to the identification of biological markers [12,13] and therapeutic targets [14, 15]. To date, several studies have applied proteomic analyses to assess protein markers in human endometrial tissue, blood, urine, and peritoneal fluid, and some differentially expressed peptides have been found to have clinical application value for providing information on the pathophysiology of endometriosis [16-19]. However, peptidomic analysis of OvE has not yet been reported. Therefore, we chose ectopic endometria and the eutopic endometria to study differentially expressed peptides. In addition, most of the previous studies aimed to identify differentially expressed mRNA and protein between the ectopic endometria and the eutopic endometria of healthy women [11]. Thus, we are the first to compare the notable pathological details of the ectopic endometria and eutopic endometria of OvE patients.

\section{Materials and Methods}

\section{Patients and samples}

Three women with OvE were enrolled in the study and their clinical information is shown in Table 1. The tissue samples of the ectopic endometrium and eutopic endometrium of each OvE woman were collected at the time of laparoscopy and curettage and all samples were confirmed by pathology. All patients signed a written informed consent form, and the study protocol was approved by the Ethics Committee of Nanjing Maternal and Child Health Care Hospital.

Peptide extraction and purification

All tissue samples were washed in isotonic phosphate-buffered saline (PBS), and a protease inhibitor mixture (Complete Mini EDTA-free, Roche, Basel, Switzerland) was added. The samples were snap-frozen in liquid nitrogen within 5 min of collection and stored until use. Endometrial samples were cut into pieces, followed by ultrasonication of the homogenate for $20 \mathrm{~min}$. Samples were centrifuged at $12,000 \mathrm{~g}$ at $4^{\circ} \mathrm{C}$ for 15 min to obtain supernatants. Centrifugal concentrators (Amicon Ultra-15, Millipore) with a molecular 


\section{Cellular Physiology Cell Physiol Biochem 2018;48:107-118 \begin{tabular}{ll|l} 
and Biochemistry & $\begin{array}{l}\text { DOI: 10.1159/000489753 } \\
\text { Published online: May 15, } 2018\end{array}$ & $\begin{array}{l}\text { @ } 2018 \text { The Author(s). Published by S. Karger AG, Basel } \\
\text { www.karger.com/cpb }\end{array}$ \\
\hline
\end{tabular}}

Xue et al.: Peptidomic Analysis of Ovarian Endometriosis

weight cutoff (MWCO) of $10 \mathrm{kDa}$ were washed with $0.5 \mathrm{~mL} \mathrm{H}_{2} \mathrm{O}$, and the supernatant was filtered through a molecular filter according to the manufacturer's instructions, with the flow-through containing the peptides. The peptide concentration of the supernatant was measured with the BCA protein assay. Lastly, the supernatant was recovered, lyophilized, and immediately frozen at $-80^{\circ} \mathrm{C}$ for subsequent experiments.

\section{Peptide desalting and TMT labeling}

The extracted peptides $(100 \mu \mathrm{g})$ from each sample were reduced with $10 \mathrm{mM}$ DTT at $60^{\circ} \mathrm{C}$ for $1 \mathrm{~h}$, followed by alkylation with $55 \mathrm{mM}$ IAA at room temperature for $45 \mathrm{~min}$. Next, the peptides were desalted and dried, and $20 \mu \mathrm{g}$ of the samples were labeled with $5 \mu \mathrm{L}$ of the TMT reagent according to the manufacturer's instructions (TMT 6-plex Label Reagent; Thermo Fisher Scientific, Waltham, MA, USA). The eutopic endometrial samples were labeled with reagents 126,127 , and 128 , and the ectopic endometrium samples were labeled with reagents 129,130 , and 131 . The labeled peptides were frozen at $-80^{\circ} \mathrm{C}$ for further liquid chromatography (LC)-tandem mass spectrometry (MS/MS) analysis.

\section{LC-MS/MS analysis}

Mass spectrometry analysis was performed as previously reported [20,21]. The labeled samples were assessed via nanoflow LC (Easy-nLC; Thermo Fisher Scientific) coupled online with an LTQ-Orbitrap Velos mass spectrometer (Thermo Fisher Scientific). Reverse-phase separation of the peptides was performed using buffer A (2\% ACN, 0.5\% acetic acid) and buffer B (80\% ACN, 0.5\% acetic acid) with the multistep linear gradient of solvent B: 4-9\% for $3 \mathrm{~min}, 9-33 \%$ for $170 \mathrm{~min}, 33 \%-50 \%$ for $10 \mathrm{~min}, 50-100 \%$ for 1 $\min , 100 \%$ for $8 \mathrm{~min}$, and $100-4 \%$ for $1 \mathrm{~min}$. Eluting peptides were identified with the mass spectrometer at $1.8 \mathrm{kV}$ voltage, which produced high-resolution broadband mass spectra. The most abundant peptide molecular ions were identified constantly with a MS/MS scan.

\section{Peptide identification and quantification}

All MS/MS spectra of the extractions were searched in a database containing 20, 194 protein sequences of the human subset (released in January 2016) with an in-house PEAKS software (version 7.0; Bioinformatics Solutions, Waterloo, Canada). The error tolerance for the precursor ion mass was $20.0 \mathrm{ppm}$, and the error tolerance for fragment ion masses was 0.1 Da. A fusion target-decoy method was used to evaluate the false discovery rate (FDR), which was controlled at $\leq 1.0 \%(-10 \log \mathrm{P} \geq 20.0)$ for both proteins and peptides. If the peptide peaks were present in at least two spectra per sample, the peptides were considered positively identified.

Relative quantifications of the derived peptides from the 6 samples were performed by TMT labeling in the PEAKS Q module. Feature detection was carried out by the expectation-maximization algorithm on each sample. Peptides were considered significantly altered between the two kinds of endometrial samples when the statistical $p$ value was $<0.05$ and when the fold change was $\geq 2$.

\section{Bioinformatics analysis}

For further research, UniProt Database release 2015_5 (http://www.uniprot.org/) was used to perform a gene ontology (GO) analysis to investigate the potential functions of the peptide protein precursors within the following three categories: cellular component, biological process, and molecular function. A pathway analysis revealed the networks in which these peptide precursors were involved. The IP/MW online tool (http://web.expasy.org/compute.pi/) was applied to calculate the isoelectric point (IP) of each peptide. The SMART (http://smart.embl-heidelberg.de/smart/batch.pl) and SABLE (http://sable.cchmc.org) online tools were used to determine if the significantly different peptide sequences were located in the conserved structural domains of their protein precursors and if their peptide segments contained secondary structure. The Open Targets Platform database (http://targetvalidation.org/) was used to investigate protein precursors associated with disease. 


\section{Cellular Physiology Cell Physiol Biochem 2018;48:107-118

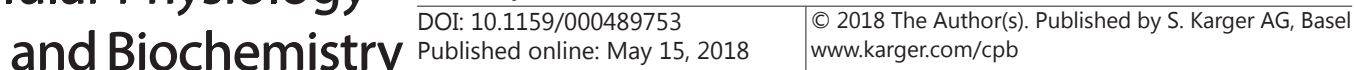

Xue et al.: Peptidomic Analysis of Ovarian Endometriosis

Cell culture and treatments

Highly differentiated ESCs were obtained from Cellbio (Shanghai, China). ESCs were cultured in highGlu Dulbecco's modified Eagle's medium (DMEM) (Gibco, Grand Island, NY, USA) supplemented with 10\% fetal bovine serum (FBS), $100 \mathrm{U} / \mathrm{mL}$ streptomycin, and $100 \mathrm{U} / \mathrm{mL}$ penicillin. Cultured cells were maintained at $37^{\circ} \mathrm{C}$ with $5 \% \mathrm{CO}_{2}$ in a humidified environment. The PDFV peptide (AGRSRKEVELIIQVT) and the control peptide (VTQEVSKIRLAIREG) were purchased from Beijing Zexiyuan Biotech Co., Ltd., China.

\section{Wound healing assays}

Wound healing assays were conducted to evaluate the migration of ESCs in vitro. ESCs were seeded in 6-well plates at a concentration of $1 \times 10^{6}$ cells/well and cultured until they reached $80-90 \%$ confluency. Then, the cell monolayers were scratched with sterile $1000-\mathrm{mL}$ pipette tips, and non-adherent cells and debris were removed by washing with PBS. Cells were treated with DMEM containing $10 \mu \mathrm{M}$ peptide (PDFV or the control peptide) and incubated in serum-free media at $37^{\circ} \mathrm{C}$ for $48 \mathrm{~h}$ to allow cells to migrate into the scratched area. Later, images were captured from three random replicates for each group after $24 \mathrm{~h}$ and 48 $\mathrm{h}$. The images from the final time points were compared with those of the $0 \mathrm{~h}$ time point to calculate the level of closure for each scratch on the basis of the distance between the two sides of the wound. Quantification of the scratched area was performed with the PS software.

\section{Transwell assay}

We performed cell invasion assays using the CytoSelect ${ }^{\mathrm{TM}}$ Cell Invasion Assay Kit (Cell Biolabs) according to the manufacturer's instructions. Eight-hundred microliters of medium containing 10\% FBS was added to the lower chamber of the invasion plate. Two hundred microliters of the cell suspension solution at a concentration of $5.0 \times 10^{5}$ cells $/ \mathrm{mL}$ with PDFV $(10 \mu \mathrm{M})$ and the control peptide $(10 \mu \mathrm{M})$ were added to the upper chamber of the plate. The cells were incubated for $48 \mathrm{~h}$ at $37^{\circ} \mathrm{C}$ with $5 \% \mathrm{CO}_{2}$. During this time, the invasive cells traversed the basement membrane layer of the chamber and attached to the bottom of the insert, whereas the non-invasive cells remained in the upper chamber. The non-invasive cells were removed carefully. The invasive cells were transferred to a clean well containing $800 \mu \mathrm{L}$ of $4 \%$ paraformaldehyde and incubated for $30 \mathrm{~min}$ at room temperature following by staining with crystal violet for $10 \mathrm{~min}$. A microscope was used to image the invasive cells.

\section{Western blotting}

ESCs were treated with PDFV and the control peptide $(10 \mu \mathrm{M})$ for $48 \mathrm{~h}$. Then, cell extracts $(40 \mu \mathrm{g})$ were obtained and resolved by $10 \%$ reducing SDS-polyacrylamide gel electrophoresis and transferred to nitrocellulose membranes. The membranes were blocked for $2 \mathrm{~h}$ at room temperature with a $3 \%$ bovine serum albumin (BSA) solution in $20 \mathrm{mM}$ Tris-HCl, pH 7.4, containing $150 \mathrm{mM} \mathrm{NaCl}$ and $0.02 \%$ Tween 20 (TBST), and the membranes were incubated overnight at $4^{\circ} \mathrm{C}$ in a 1:500 dilution of E-cadherin antibody (Cell Signaling Technology, Danvers, MA, USA) and a 1:1000 dilution of $\beta$-actin (Cell Signaling Technology) in TBST containing $0.2 \%$ BSA. The membranes were washed five times with TBST and then incubated with alkaline phosphatase-conjugated secondary antibody (1:10, 000 dilution; Cell Signaling Technology). The bands were visualized using a 5-bromo-4-chloro-3-indolyl phosphate/nitro blue tetrazolium substrate solution.

\section{Statistical analysis}

Data are presented as the mean \pm standard deviation and were analyzed with one-way analysis of variance followed by the Tukey-Kramer multiple comparison test. All experiments were performed in triplicate. Differences of $p<0.05$ were considered significant.

\section{Results}

Identification of differentially expressed peptides in the endometria

A total of 491 peptides were identified with significant differences between the ectopic and eutopic endometrial samples ( $p<0.05$, absolute fold change $\geq 2$ ). The 491 peptides contained 80 upregulated peptides and 374 downregulated peptides, with 20 peptides detected only in the ectopic endometrial samples and 17 peptides detected only in the eutopic endometrium samples. The cluster analysis (heatmap) and volcano plot of the 491 peptides 
are shown in Fig. $1 \mathrm{~A}$ and $\mathrm{B}$, and a list of the 20 abundant peptides that were differentially expressed ( $p$ value) in the two kinds of endometria is shown in Table 2.

Details of the 491 differentially expressed peptides

The molecular weights (MWs) and IPs of the 491 differentially expressed peptides $(p<0.05$ and $>$ a 2 -fold change) are shown in Fig. 2A and $\mathrm{B}$. In addition, a scatter plot of the MW versus IP is shown in Fig. 2C. It was observed that the MWs of the 491 peptides were mainly distributed from 500 to $700(25 \%)$, and the largest proportion of peptide IPs ranged from 5 to 6 , accounting for $31 \%$ of all peptides. We next searched for cleavage sites in all differentially expressed peptides to investigate possible functional changes in the endometrial tissues of OvE. The left side (C-terminus) and the right side (N-terminus) of each peptide was denoted P1 and P1', respectively. Alanine (A) was the most common P1 amino acid, being present in $18 \%$ of the peptides (Fig. 2D). Leucine (L) was the most common P1' amino acid, being present in $14 \%$ of the peptides (Fig. 2D).

Functional prediction by bioinformatics

To determine whether these differentially expressed peptides were associated with OvE, we performed GO and pathway analyses to determine potential roles for these peptides based on thier precursor proteins. Most of the peptide precursors were categorized as follows: membrane, $\mathrm{Z}$ disc, cytoplasm, and extracellular matrix (Fig. 3A). The top five most relevant biological

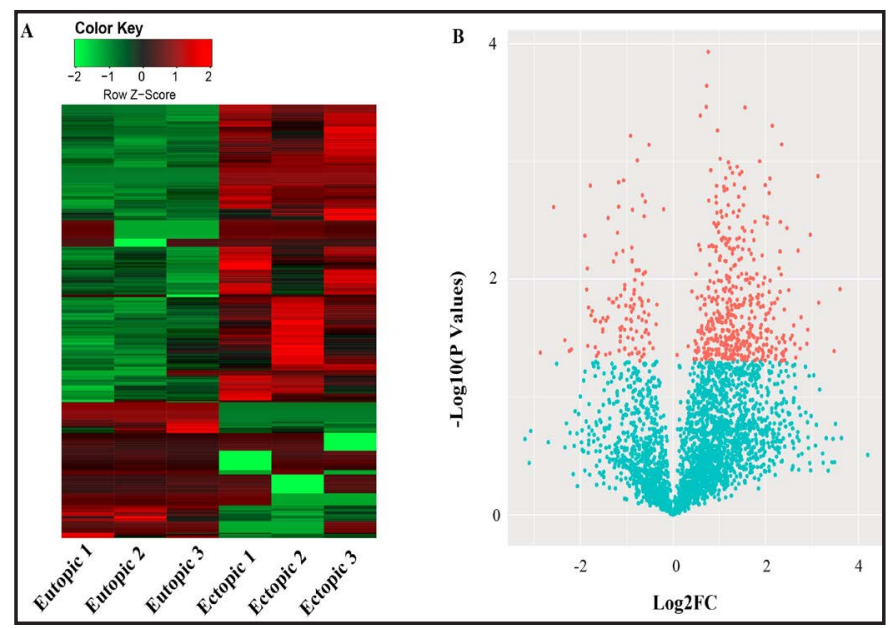

Fig. 1. Differentially expressed peptides in ectopic tissues compared with eutopic endometria tissues in ovarian endometriosis patients. The heatmap (A) and volcano plot (B) of the 491 peptides (more than 2 -fold change and $p<0.05$ ).

Table 2. Twenty of the abundant peptides that are differentially expressed in the endometrium of OvE patients

\begin{tabular}{lcccc}
\hline Protein & Peptide & Fold change & p-value & FDR \\
\hline CALD1 & SAKPTKPAASDLPVPAEGVRNIK & 3.59 & 0.016 & 0.19 \\
CALD1 & GNVFSSPTAAGTPNKETAGLK & 3.581 & 0.011 & 0.18 \\
IGSF1 & NGDFIISNVDGKGTG & 3.851 & 0.017 & 0.19 \\
SCRIB & ALPPEIGGCVALSVLSL & 3.36 & 0.031 & 0.24 \\
AMACR & ALQGISVVELSGLA & 3.36 & 0.031 & 0.24 \\
EXT1 & LQAACVPVMLSNG & 3.176 & 0.014 & 0.19 \\
NOS3 & VLEQFPSVALPAPLLLTQL & 2.151 & 0.002 & 0.08 \\
VCAM1 & AGRSRKEVELIIQVT & -2.439 & 0.007 & 0.13 \\
\hline
\end{tabular}

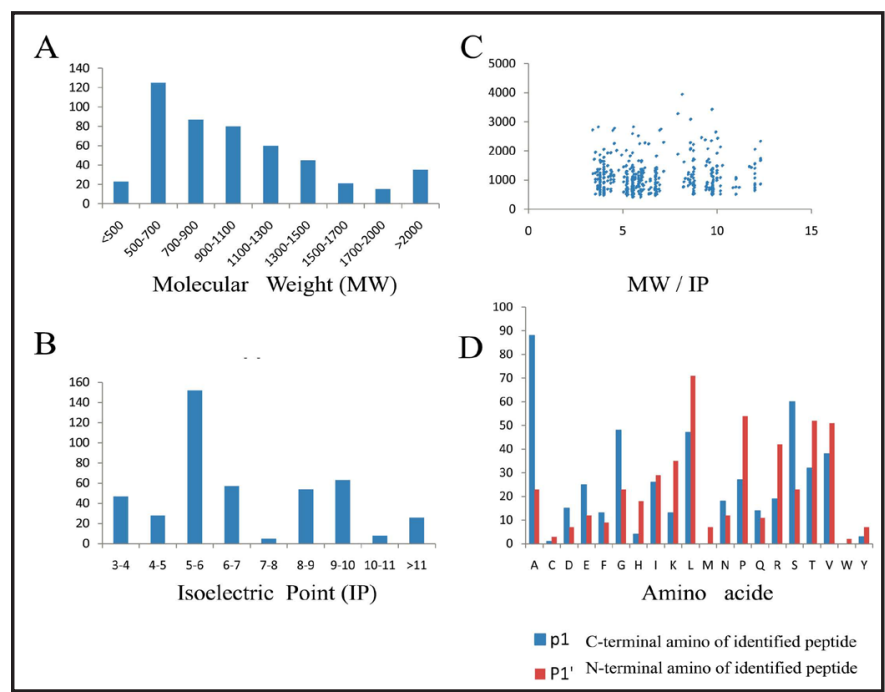

Fig. 2. Features of the differentially expressed peptides. (A) Molecular weights (MWs) of the peptides. (B) Isoelectric points (IPs) of the peptides. (C) Scatter plot of the MWs versus the IPs. (D) Distributions of the left-side (i.e., C-term) and right-side (i.e., $\mathrm{N}$-term) amino acids of the identified peptides. 
functions were negative regulation of protein phosphorylation, spinal cord development, sensory perception of light stimulus, positive regulation of gene expression, and homophilic cell adhesion via plasma membrane adhesion molecules (Fig. 3B). The molecular functions of the peptide precursors mainly included chromatin binding, actin binding, ATP binding, protein binding, and extracellular matrix structural constituent (Fig. 3C). In addition, the pathway analysis showed that the top five networks of these peptide precursors were (i) focal adhesions, (ii) the MAPK signaling pathway, (iii) dilated cardiomyopathy, (iv) insulin secretion, and (v) platelet activation (Fig. 3D).

\section{Associated peptides and precursor proteins}

A total of 491 peptides originated from 392 precursor proteins. SMART and SABLE showed that 42 peptide sequences were located in the conserved structural domains of their protein precursors. Meanwhile, their peptide segments contained secondary structure, which indicated that the 42 peptides were derived from the functional domains of their corresponding precursor proteins. The UniProt database showed that 2 of the 392 precursor proteins, namely, thymosin beta-4 (TMSB4X) and elastin (ELN), were associated with the cell proliferation process. Thymosin beta- 4 was also associated with regulation of cell migration and negative regulation of the extrinsic apoptotic signaling pathway. Nitric oxide synthase (NOS3) was associated with angiogenesis. Additionally, five peptides were identified to be as-

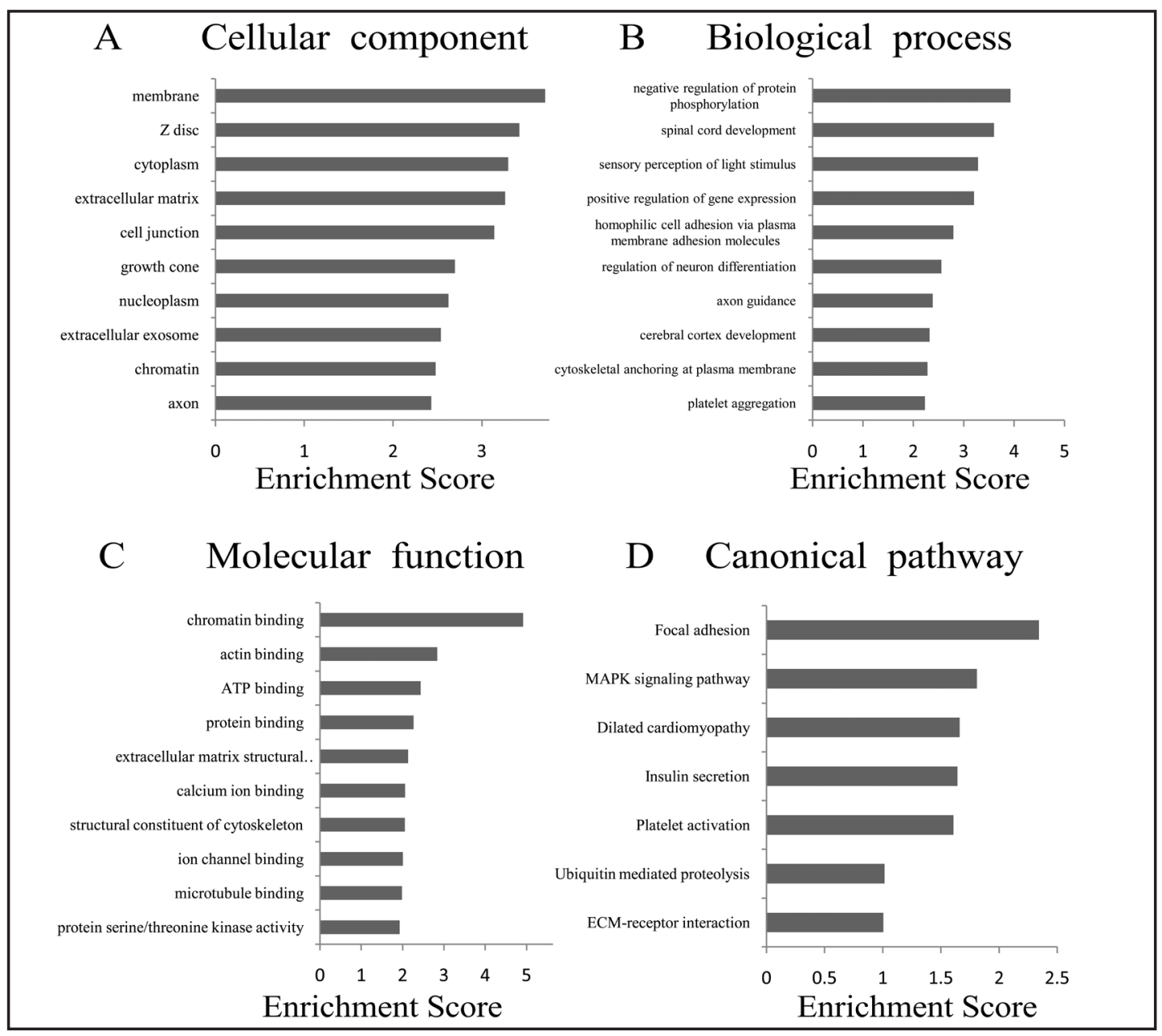

Fig. 3. Peptide precursor categories of the 448 differentially expressed peptides identified in the liquid chromatography-tandem mass spectrometry analyses. (A) Cellular component. (B) Biological process. (C) Molecular function. (D) Canonical pathway. 


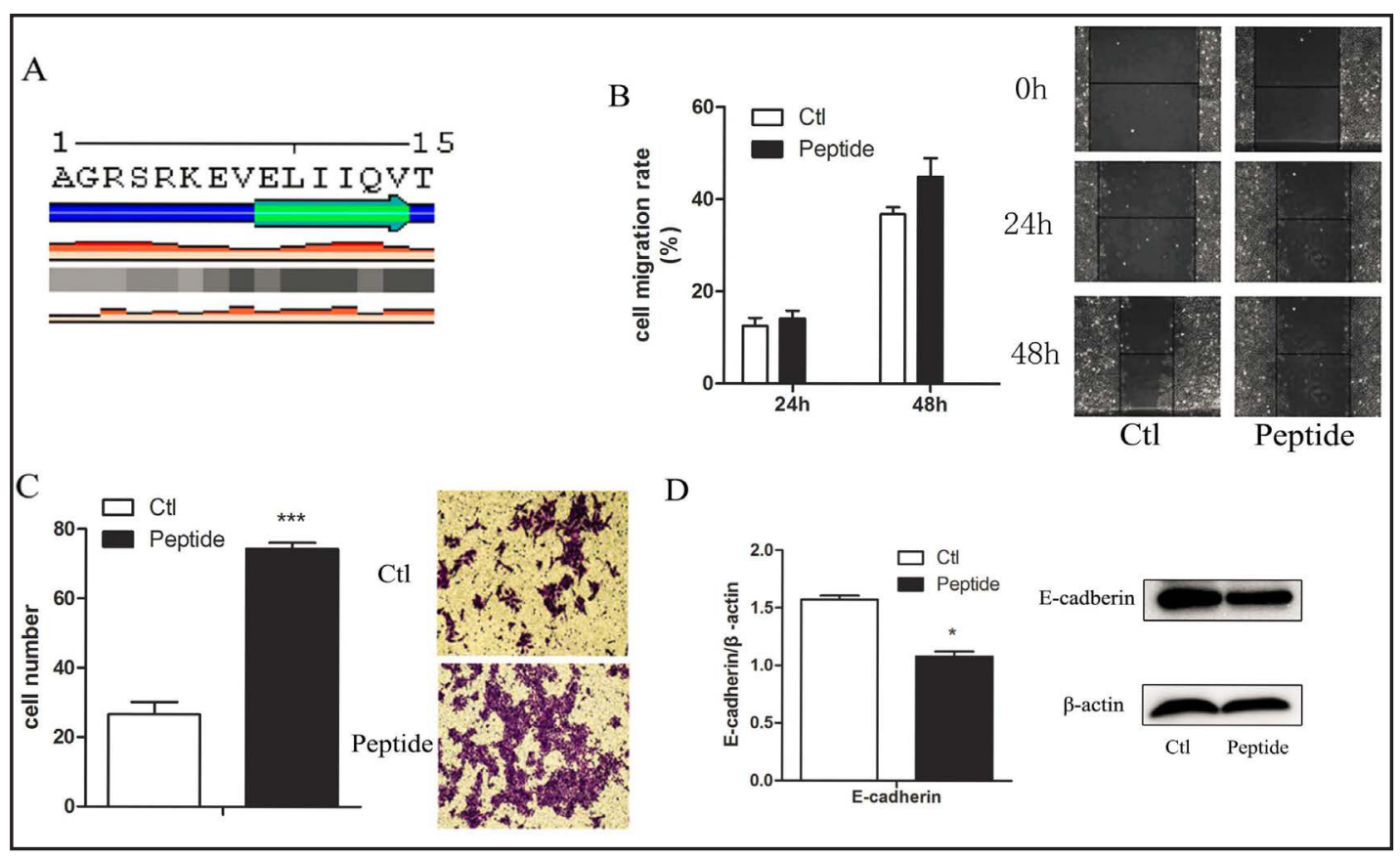

Fig. 4. Function analysis of peptides derived from VCAM-1 (PDFV). (A) The conserved functional domains of PDFV: AGRSRKEVELIIQVT (P19320/VCAM1). (B) Wound healing assay. (C) Transwell assay. (D) Western blotting.

sociated with OvE according to their precursor proteins through the Open Targets Platform database despite their unclear functions: AGRSRKEVELIIQVT (P19320/VCAM-1) (Fig. 4A), VLEQFPSVALPAPLLLTQL (P29474/NOS3), N G D F I I S N V D G KGTG (Q8N6C5/ IGSF1), GNVFSSPTAAGTPNKETAGLK (Q05682-5/CALD1), and SAKPTKPAAS-
Table 3. Protein precursors and identified peptides related to OvE

\begin{tabular}{lcccc}
\hline Protein & Peptide & Fold change & p-value & FDR \\
\hline HP1B3 & EDVLPL & 12.163 & 0.012 & 0.178 \\
VIME & SLPLVD & 11.125 & 0.041 & 0.254 \\
FMNL1 & PGAAP & 8.839 & 0.016 & 0.193 \\
H0Y2V8 & VAQILDFIS & 8.735 & 0.001 & 0.084 \\
PGBM & VHAGR & 8.735 & 0.001 & 0.084 \\
PRC2C & PPPAPSI & 7.794 & 0.004 & 0.104 \\
H2A2C & 7.505 & 0.027 & 0.231 \\
TTC28 & AGLQFPVGRVHRLL & 7.505 & 0.027 & 0.231 \\
TICN2 & MLHQVL & 7.407 & 0.035 & 0.246 \\
FA65A & LLAAAALAEGDAK & 6.791 & 0.021 & 0.215 \\
F5H0F9 & DGLRALSSLLVH & -7.29 & 0.042 & 0.256 \\
H1T & MASVH & -5.98 & 0.002 & 0.101 \\
SPEF2 & AGVAAM & -5.051 & 0.033 & 0.241 \\
CNN1 & SLQKDFPIQILSIDTLV & -4.718 & 0.041 & 0.254 \\
HERC2 & NIIGLQMGTNK & -4.579 & 0.04 & 0.252 \\
J3QSS3 & LGHGSDDHV & -4.579 & 0.04 & 0.252 \\
CO6A3 & GVGATCV & -4.579 & 0.04 & 0.252 \\
SH2B1 & PAEFRAAPLQGMLPGLLAPLRTL & -3.742 & 0.004 & 0.104 \\
TACC2 & PHDLSLESCRVGGPLA & -3.742 & 0.004 & 0.104 \\
ADCY7 & PSTASHLLVLGSLMGGFTTPSVRVGLQLLANAVI & -3.742 & 0.004 & 0.104 \\
\hline
\end{tabular}

D L P VPAE GVR N I K

(Q05682-5/CALD1) (Table 3).

Because cell migration plays an important role in endometriosis, we examined whether PDFV affected the migration of ESCs with wound healing assays. In vitro, the migration of ESCs was evaluated in wounded spaces on culture plates. When ESCs were treated with PDFV for $24 \mathrm{~h}$ and $48 \mathrm{~h}$ under serum-free conditions, cell migration increased relative to cells treated with the control peptide under serum-free conditions (Fig. 4B). This result was also confirmed in Transwell assays, suggesting that PDFV (10 $\mu \mathrm{M})$ could increase the invasiveness of ESCs (Fig. 4C). Because E-cadherin protein is important for migration and plays a pivotal role in endometriosis [22], we next analyzed E-cadherin expression using western blot. As shown in Fig. 4D, PDFV treatment reduced the expression of E-cadherin. 


\section{Discussion}

Endometriosis is one of the most common gynecological diseases, with an incidence of approximately $10 \%$ in women of reproductive age. In recent years, accumulating evidence has suggested that significant biological differences exist between the eutopic endometria of healthy women and the ectopic endometria of women with endometriosis [3, 23], but few studies have identified significant biochemical differences between the ectopic endometriotic lesions and the putative eutopic precursors [24]. Thus, in our study, we analyzed the differentially expressed peptides between the eutopic and ectopic endometria of OvE patients, a common subtype of endometriosis. To our knowledge, our study is the first qualitative and quantitative comparison of the differentially expressed peptides of the ectopic and eutopic endometria of OvE patients using peptidomics, which will pave the way for future study of the pathogenesis of OvE.

In this study, we collected ectopic endometrial samples and ectopic endometrial samples from OvE patients for peptide extractions with 10-kDa MWCO filters, which could ensure the purity of the extracted peptides. Finally, we detected 3668 peptides in the six samples, indicating that centrifugal ultrafiltration with the 10-kDa MWCO filters is an effective method for extracting low-molecular-mass peptides for future functional studies of the identified peptides. A total of 491 peptides were significantly different between the two groups $(p<0.05$ and a $>2$-fold change). The MWs of the 491 peptides were mainly distributed from 500 to 700 , and the MWs of $99 \%$ of the peptides were less than 3000, which again highlights the effectiveness of the MWCO filter. The largest proportion of peptide IPs ranged from 5 to 6 , accounting for $31 \%$ of all peptides. Some studies have shown that an acidic amino acid plays a more important role in cell migration and angiopoiesis than a non-acidic amino acid. Alanine (A) is the most common P1 amino acid, accounting for $18 \%$ of the peptides, and leucine (L) is the most common P1' amino acid, accounting for $14 \%$ of the peptides. Notably, lysine is found in the a $\beta$-sheet, which plays an important role in the processes of protein folding, protein stability, and molecular recognition. Additionally, L and A are both hydrophobic amino acids, which are not easily dissolved and are involved in interactions such as those between an enzyme and substrate or between an antibody and antigen. The literature also suggests that hydrophobic residues significantly contribute to receptor activation, G-protein coupling, and the oligomerization process and that hydrophobic residues might modulate protein partner activity or stability at the inner membrane [25]. Therefore, it suggests that these identified peptides may be essential for regulating OvE progression.

We then performed bioinformatics analyses of the peptidome profiling to obtain the functions and mechanisms of these significantly differentially expressed peptides in regulating the early progress of endometriosis formation. Firstly, the GO analysis revealed that the molecular functions of the peptides precursors are mainly concentrated in the following categories: actin binding, ATP binding, and extracellular matrix structural constituent. Some studies have indicated that structural actin cytoskeleton characteristics play crucial roles in permissive regulation of the cell matrix adhesive interactions and cell migration behavior [26] and that ATP regresses endometriotic tissues in a rat endometriosis model [27]. Given that migration is a necessary process during endometriosis and that migration requires energy consumption, these peptides may play important roles in the migration processes of endometriosis. Secondly, by analyzing the cellular component category, we found that the protein precursors are located throughout the subcellular regions, which indicates that these peptides exist in various cellular components. Moreover, the main cellular component of the identified peptides was associated with the membrane structure, which is consistent with the results of Wu et al [28].. This is understandable because many pathways function via the membrane. Thirdly, homophilic cell adhesion via plasma membrane adhesion molecules is the most important biological function, which is significantly associated with the formation of endometriosis because adhesion is a known feature of endometriosis [29]. Lastly, the canonical pathways were generated using the IPA software, and the "MAPK signaling pathway" was identified as a highly prevalent term because the MAPK signaling pathway

\section{KARGER}




\section{Cellular Physiology Cell Physiol Biochem 2018;48:107-118 \\ \begin{tabular}{c|c|c|} 
DOI: 10.1159/000489753 & O 2018 The Author(s). Published by S. Karger AG, Basel \\
www.karger.com/cpb
\end{tabular} \\ Xue et al.: Peptidomic Analysis of Ovarian Endometriosis}

functions in the control of cell division, gene expression, cell movement, and survival to induce endometriosis [30, 31].

Subsequently, we analyzed the 491 peptides with the SMART and SABLE tools, with the results showing that 42 peptide sequences were located in the conserved structural domains of their protein precursors and that their peptide segments contained secondary structure. The GO analysis of the precursor proteins, from which the 42 peptides were derived, showed that thymosin beta-4 (TMSB4X) and elastin (ELN) were associated with the cell proliferation process. Thymosin beta- 4 was also associated with cell migration and negative regulation of the extrinsic apoptotic signaling pathway. NOS3 was associated with angiogenesis. Additionally, another 5 precursor proteins of the peptides were reported to be associated with endometriosis.

Through a further literature search, we found that increasing evidence highlights the potentially crucial roles of VCAM-1 in the pathological process underlying endometriosis [32]. NOS3 may modulate angiogenesis and influence individual susceptibility to endometriosis, and it is widely accepted that angiogenesis plays an essential role in the growth and survival of endometriotic lesions. Moreover, NOS3 has also been reported to be associated with advanced stage endometriosis in a Korean population [33, 34]. Previous studies have shown altered levels of the CALD1 gene (encoding the protein caldesmon) in endometriosis and that precursor protein of caldesmon is a possible predictor of endometrial dysregulation in patients with endometriosis [35, 36]. The IGSF21 gene is also implicated in the pathophysiology of endometriosis [37]. Another study showed upregulation of the thymosin beta-4 protein in experimentally induced uterine adenomyosis in mice, which was responsible for the disintegration of the musculature during the development of adenomyosis [38]. Altered elastin protein distributions in disease states may help to explain symptoms such as dysmenorrhea in uterine endometriosis [39]. In summary, these 5 peptides have caught our attention due to their possible roles in the formation of OvE.

Here, we found that VCAM-1, the precursor protein of PDFV, is essential for the survival of endometriotic implants and the development of endometriosis because blood is crucial for distributing nutrients and growth factors and for promoting recruitment of inflammatory cells to endometriotic lesions [40]. Moreover, PDFV has been verified in our study to enhance human ESC migration and invasion in vitro, which is crucial for the development of endometriotic lesions. In addition, PDFV also reduced the protein expression level of E-cadherin, thus promoting ESC migration. E-cadherin has been confirmed to be involved in the processes of cancer [41] and endometriosis [22]. However, our finding is contrary to the research by Reichert Faria et al, who found impaired adhesion that was supported by diminished immunohistochemical expression of VCAM-1, which indicated that VCAM1 promoted adhesion. From our view, this result is understandable because peptides can perform functions that are completely different from those of their precursor proteins [42, 43].

E-cadherin is an important factor of the cell-cell adherence junction and regulates tumor cell progression, migration, and metastasis via maintenance of cell-cell interactions. Some studies have also indicated that endometriotic epithelial cells show decreased E-cadherin expression, which is a representative mesenchymal marker. Publicly available microarray data sets (GSE5108 and GSE7305 submitted on Gene Expression Omnibus) show that E-cadherin mRNA expression is significantly reduced in endometriotic tissue compared with normal endometrium [44]. These data indicate that the effect of PDFV on ESCs may decrease the expression of E-cadherin, thereby causing the formation of OvE.

Moreover, VCAM-1 belongs to a family of cell adhesion molecules that are involved in cell-cell interactions and mediate various immune and inflammatory processes [45]. VCAM-1 and its counter receptors are expressed by both epithelial cells, such as eutopic and ectopic endometrial cells, and by cells of the immune system. Thus, VCAM-1 and its counter receptors may play roles in both the interaction between the endometrial cell and the peritoneal surface and the inflammation and immunological reaction that accompanies the disease process [46]. 
There are some limitations to our study. Firstly, we used the $p$ value to screen differentially expressed peptides between the ectopic and eutopic endometria samples. Although FDR is more accurate than the $p$ value for detecting differentially expressed peptides, we would get very few peptides though FDR. Because we found that some studies also applied the $p$ value to peptidomic analysis $[28,47]$, we used $p$ values in our study as well. There were many false positives in our study with this method and only the PDFV has been validated by cell experiments; the other peptides were reported purely on the basis of the $p$ value and without any further validation. Secondly, although we used $3 \mathrm{OvE}$ tissue samples, one subtype of endometriosis, to analyze the differentially expressed peptides and some of the heterogeneity of endometriosis population was ruled out, it is still a small sample size and these sample sizes are at best minimal. Thus, further studies of OvE and peptides are needed to evaluate the peptides and OvE patients.

In summary, this study screened differentially expressed peptides preliminarily based on the peptidomics approach using eutopic endometrial samples and ectopic endometrial samples from women with OvE and has provided new insights into the search for sensitive and non-invasive tumor markers and therapeutic targets for OvE. In a future study, we will aim to validate the potential value of the above 5 peptides as early diagnostic markers or therapeutic targets of OvE by collecting a considerable number of clinical specimens. Nonetheless, additional studies are needed to further demonstrate the role of PDFV in OvE and the relationship between PDFV and E-cadherin.

\section{Acknowledgements}

This work was funded by grants from the National Natural Science Foundation of China (Grant Nos. 81401176, 81402139, 81501222 and 81602285) and the Natural Science Foundation of Jiangsu Province (BK20140085).

\section{Disclosure Statement}

The authors declare that no conflict of interests exists.

\section{References}

1 Abbas S, Ihle P, Koster I, Schubert I: Prevalence and incidence of diagnosed endometriosis and risk of endometriosis in patients with endometriosis-related symptoms: findings from a statutory health insurance-based cohort in Germany. Eur J Obstet Gynecol Reprod Biol 2012;160:79-83.

2 Sampson JA: Metastatic or Embolic Endometriosis, due to the Menstrual Dissemination of Endometrial Tissue into the Venous Circulation. Am J Pathol 1927;3:93-110 143.

-3 O DF, Roskams T, Van den Eynde K, Vanhie A, Peterse DP, Meuleman C, Tomassetti C, Peeraer K, D’Hooghe TM, Fassbender A: The Presence of Endometrial Cells in Peritoneal Fluid of Women With and Without Endometriosis. Reprod Sci 2017;24:242-251.

4 Nisolle M, Donnez J: Peritoneal endometriosis, ovarian endometriosis, and adenomyotic nodules of the rectovaginal septum are three different entities. Fertil Steril 1997;68:585-596.

5 Ploteau S, Cano-Sancho G, Volteau C, Legrand A, Venisseau A, Vacher V, Marchand P, Le Bizec B, Antignac JP: Associations between internal exposure levels of persistent organic pollutants in adipose tissue and deep infiltrating endometriosis with or without concurrent ovarian endometrioma. Environ Int 2017;108:195203.

6 Sanchez AM, Vigano P, Somigliana E, Panina-Bordignon P, Vercellini P, Candiani M: The distinguishing cellular and molecular features of the endometriotic ovarian cyst: from pathophysiology to the potential endometrioma-mediated damage to the ovary. Hum Reprod Update 2014;20:217-230. 


\section{Cellular Physiology Cell Physiol Biochem 2018;48:107-118

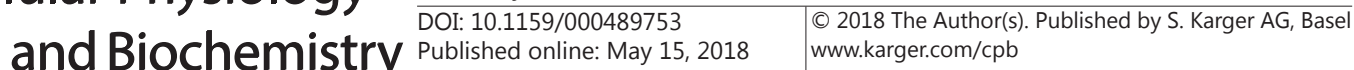

Xue et al.: Peptidomic Analysis of Ovarian Endometriosis

7 Vercellini P, S DEM, Somigliana E, Buggio L, Frattaruolo MP, Fedele L: Long-term adjuvant therapy for the prevention of postoperative endometrioma recurrence: a systematic review and meta-analysis. Acta Obstet Gynecol Scand 2013;92:8-16.

8 Yin P, Knolhoff AM, Rosenberg HJ, Millet LJ, Gillette MU, Sweedler JV: Peptidomic analyses of mouse astrocytic cell lines and rat primary cultured astrocytes. J Proteome Res 2012;11:3965-3973.

-9 Taylor SW, Nikoulina SE, Andon NL, Lowe C: Peptidomic profiling of secreted products from pancreatic islet culture results in a higher yield of full-length peptide hormones than found using cell lysis procedures. J Proteome Res 2013;12:3610-3619.

10 Tuerxun H, Zhang Y, Ji F, Aili A, Yang X, Ding Y: Application of two-dimensional electrophoresis and mass spectrometry to screen endometriosis-related proteins. Mol Med Rep 2014;10:95-100.

11 Fassbender A, Verbeeck N, Bornigen D, Kyama CM, Bokor A, Vodolazkaia A, Peeraer K, Tomassetti C, Meuleman C, Gevaert O, Van de Plas R, Ojeda F, De Moor B, Moreau Y, Waelkens E, D’Hooghe TM: Combined mRNA microarray and proteomic analysis of eutopic endometrium of women with and without endometriosis. Hum Reprod 2012;27:2020-2029.

12 Bhalla S, Verma R, Kaur H, Kumar R, Usmani SS, Sharma S, Raghava GPS: CancerPDF: A repository of cancerassociated peptidome found in human biofluids. Sci Rep 2017;7:1511.

13 Villanueva J, Shaffer DR, Philip J, Chaparro CA, Erdjument-Bromage H, Olshen AB, Fleisher M, Lilja H, Brogi E, Boyd J, Sanchez-Carbayo M, Holland EC, Cordon-Cardo C, Scher HI, Tempst P: Differential exoprotease activities confer tumor-specific serum peptidome patterns. J Clin Invest 2006;116:271-284.

14 Dhanik A, Kirshner JR, MacDonald D, Thurston G, Lin HC, Murphy AJ, Zhang W: In-silico discovery of cancerspecific peptide-HLA complexes for targeted therapy. BMC Bioinformatics 2016;17:286.

15 Hardt M, Thomas LR, Dixon SE, Newport G, Agabian N, Prakobphol A, Hall SC, Witkowska HE, Fisher SJ: Toward defining the human parotid gland salivary proteome and peptidome: identification and characterization using 2D SDS-PAGE, ultrafiltration, HPLC, and mass spectrometry. Biochemistry 2005;44:2885-2899.

16 Ural UM, Tekin YB, Cure M, Sahin FK: Serum YKL-40 levels as a novel marker of inflammation in patients with endometriosis. Clin Exp Obstet Gynecol 2015;42:495-497.

17 Liu E, Nisenblat V, Farquhar C, Fraser I, Bossuyt PM, Johnson N, Hull ML: Urinary biomarkers for the non-invasive diagnosis of endometriosis. Cochrane Database Syst Rev 2015;10.1002/14651858. CD012019CD012019.

18 Bilibio JP, Cunha-Filho JS: Serum Prolactin and CA-125 Levels as Biomarkers of Peritoneal Endometriosis. Gynecol Obstet Invest 2016;81:96.

19 Vehmas AP, Muth-Pawlak D, Huhtinen K, Saloniemi-Heinonen T, Jaakkola K, Laajala TD, Kaprio H, Suvitie PA, Aittokallio T, Siitari H, Perheentupa A, Poutanen M, Corthals GL: Ovarian endometriosis signatures established through discovery and directed mass spectrometry analysis. J Proteome Res 2014;13:4983-4994.

20 Trenchevska O, Yassine HN, Borges CR, Nelson RW, Nedelkov D: Development of quantitative mass spectrometric immunoassay for serum amyloid A. Biomarkers 2016;10.1080/1354750X.2016.12015331-9.

21 Czech H, Schepler C, Klingbeil S, Ehlert S, Howell J, Zimmermann R: Resolving Coffee Roasting-Degree Phases Based on the Analysis of Volatile Compounds in the Roasting Off-Gas by Photoionization Time-of-Flight Mass Spectrometry (PI-TOFMS) and Statistical Data Analysis: Toward a PI-TOFMS Roasting Model. J Agric Food Chem 2016;64:5223-5231.

22 Matsuzaki S, Darcha C, Maleysson E, Canis M, Mage G: Impaired down-regulation of E-cadherin and betacatenin protein expression in endometrial epithelial cells in the mid-secretory endometrium of infertile patients with endometriosis. J Clin Endocrinol Metab 2010;95:3437-3445.

-23 Kasvandik S, Samuel K, Peters M, Eimre M, Peet N, Roost AM, Padrik L, Paju K, Peil L, Salumets A: Deep Quantitative Proteomics Reveals Extensive Metabolic Reprogramming and Cancer-Like Changes of Ectopic Endometriotic Stromal Cells. J Proteome Res 2016;15:572-584.

24 Sharpe-Timms KL: Endometrial anomalies in women with endometriosis. Ann N Y Acad Sci 2001;943:131147.

-25 Caltabiano G, Gonzalez A, Cordomi A, Campillo M, Pardo L: The role of hydrophobic amino acids in the structure and function of the rhodopsin family of $G$ protein-coupled receptors. Methods Enzymol 2013;520:99-115.

-26 Frismantiene A, Kyriakakis E, Dasen B, Erne P, Resink TJ, Philippova M: Actin cytoskeleton regulates functional anchorage-migration switch during T-cadherin-induced phenotype modulation of vascular smooth muscle cells. Cell Adh Migr 2018;12:69-85. 


\section{Cellular Physiology Cell Physiol Biochem 2018;48:107-118 \begin{tabular}{l|l} 
and Biochemistry Published 10.1159/000489753 & $\begin{array}{l}\text { C) } 2018 \text { The Author(s). Published by S. Karger AG, Basel } \\
\text { www.karger.com/cpb }\end{array}$
\end{tabular} \\ Xue et al.: Peptidomic Analysis of Ovarian Endometriosis}

-27 Zhang C, Gao L, Yi Y, Han H, Cheng H, Ye X, Ma R, Sun K, Cui H, Chang X: Adenosine Triphosphate Regresses Endometrial Explants in a Rat Model of Endometriosis. Reprod Sci 2016;23:924-930.

28 Wu L, Li H, Li X, Chen Y, Zhang Q, Cheng Z, Fan Y, Song G, Qian L: Peptidomic Analysis of Cultured Cardiomyocytes Exposed to Acute Ischemic-Hypoxia. Cell Physiol Biochem 2017;41:358-368.

-29 Sundqvist J, Andersson KL, Scarselli G, Gemzell-Danielsson K, Lalitkumar PG: Expression of adhesion, attachment and invasion markers in eutopic and ectopic endometrium: a link to the aetiology of endometriosis. Hum Reprod 2012;27:2737-2746.

30 Uimari O, Rahmioglu N, Nyholt DR, Vincent K, Missmer SA, Becker C, Morris AP, Montgomery GW, Zondervan KT: Genome-wide genetic analyses highlight mitogen-activated protein kinase (MAPK) signaling in the pathogenesis of endometriosis. Hum Reprod 2017;32:780-793.

-31 Santulli P, Marcellin L, Tosti C, Chouzenoux S, Cerles O, Borghese B, Batteux F, Chapron C: MAP kinases and the inflammatory signaling cascade as targets for the treatment of endometriosis? Expert Opin Ther Targets 2015;19:1465-1483.

-32 Kim KH, Park JK, Choi YW, Kim YH, Lee EN, Lee JR, Kim HS, Baek SY, Kim BS, Lee KS, Yoon S: Hexane extract of aged black garlic reduces cell proliferation and attenuates the expression of ICAM-1 and VCAM1 in TNFalpha-activated human endometrial stromal cells. Int J Mol Med 2013;32:67-78.

33 Kim H, Ku SY, Kim SH, Lee GH, Choi YM, Kim JM, Lee TH, Moon SY: Endothelial nitric oxide synthase gene Glu298Asp polymorphism is associated with advanced stage endometriosis. Hum Reprod 2009;24:26562659.

34 Wu MY, Chao KH, Yang JH, Lee TH, Yang YS, Ho HN: Nitric oxide synthesis is increased in the endometrial tissue of women with endometriosis. Hum Reprod 2003;18:2668-2671.

-35 Meola J, Hidalgo Gdos S, Silva JC, Silva LE, Paz CC, Ferriani RA: Caldesmon: new insights for diagnosing endometriosis. Biol Reprod 2013;88:122.

-36 Gupta D, Hull ML, Fraser I, Miller L, Bossuyt PM, Johnson N, Nisenblat V: Endometrial biomarkers for the non-invasive diagnosis of endometriosis. Cochrane Database Syst Rev 2016;4:CD012165.

-37 Naqvi H, Ilagan Y, Krikun G, Taylor HS: Altered genome-wide methylation in endometriosis. Reprod Sci 2014;21:1237-1243.

-38 Kawahara R, Matsuda M, Imaoka T, Mori T: Up-regulation of thymosin beta 4 gene expression in experimentally-induced uterine adenomyosis in mice. In vivo 2003;17:561-565.

-39 Zheng WQ, Ma R, Zheng JM, Gong ZJ: Elastin distribution in the normal uterus, uterine leiomyomas, adenomyosis and adenomyomas: a comparison. Anal Quant Cytol Histol 2006;28:115-120.

40 Agostinis C, Zorzet S, De Leo R, Zauli G, De Seta F, Bulla R: The combination of N-acetyl cysteine, alphalipoic acid, and bromelain shows high anti-inflammatory properties in novel in vivo and in vitro models of endometriosis. Mediators Inflamm 2015;2015:918089.

41 Wu TC: The role of vascular cell adhesion molecule-1 in tumor immune evasion. Cancer Res 2007;67:60036006.

42 Dumont F, Bischoff P: Non-erythropoietic tissue-protective peptides derived from erythropoietin: W02009094172. Expert Opin Ther Pat 2010;20:715-723.

43 Liu Y, Luo B, Shi R, Wang J, Liu Z, Liu W, Wang S, Zhang Z: Nonerythropoietic Erythropoietin-Derived Peptide Suppresses Adipogenesis, Inflammation, Obesity and Insulin Resistance. Sci Rep 2015;5:15134.

44 Yang H, Kang K, Cheng C, Mamillapalli R, Taylor HS: Integrative Analysis Reveals Regulatory Programs in Endometriosis. Reprod Sci 2015;22:1060-1072.

-45 Jung WC, Jang YJ, Kim JH, Park SS, Park SH, Kim SJ, Mok YJ, Kim CS: Expression of intercellular adhesion molecule-1 and e-selectin in gastric cancer and their clinical significance. J Gastric Cancer 2012;12:140148.

46 Kuessel L, Wenzl R, Proestling K, Balendran S, Pateisky P, Yotova s, Yerlikaya G, Streubel B, Husslein H: Soluble VCAM-1/soluble ICAM-1 ratio is a promising biomarker for diagnosing endometriosis. Hum Reprod 2017;32:770-779.

47 Li X, Wu LJ, Gu M, Chen YM, Zhang QJ, Li H, Cheng ZJ, Hu P, Han SP, Yu ZB, Qian LM: Peptidomic Analysis of Amniotic Fluid for Identification of Putative Bioactive Peptides in Ventricular Septal Defect. Cell Physiol Biochem 2016;38:1999-2014. 